\title{
DIGITAL RECORDING AND NON-DESTRUCTIVE TECHNIQUES FOR THE UNDERSTANDING OF STRUCTURAL PERFORMANCE FOR REHABILITATING HISTORIC STRUCTURES AT THE KATHMANDU VALLEY AFTER GORKHA EARTHQUAKE 2015
}

\author{
S. Shrestha ${ }^{\mathrm{a}, *}$, M. Reina Ortiz ${ }^{\mathrm{a}}$, M. Gutland ${ }^{\mathrm{b}}$, R. Napolitano ${ }^{\mathrm{c}}$, I. M. Morris ${ }^{\mathrm{c}}$, M. Santana Quintero ${ }^{\mathrm{d}}$, J. Erochko ${ }^{\mathrm{b}}, \mathrm{S}_{\text {. Kawan }}{ }^{\mathrm{e}}$,

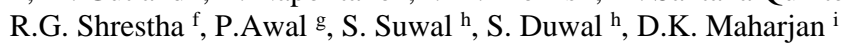 \\ ${ }^{a}$ Carleton Immersive Media Studio (CIMS), Carleton University, 1125 Colonel by drive, Ottawa, On, K1S 5B6 Canada, \\ sujan.shrestha@carleton.ca \\ ${ }^{\mathrm{b}}$ Department of Civil and Env. Engineering, Carleton University, 1125 Colonel by drive, Ottawa, On, K1S 5B6 Canada, \\ Jeffrey.Erochko@carleton.ca \\ ${ }^{c}$ Department of Civil and Env. Engineering, Princeton University, E-208 E-Quad Princeton, NJ 08544, USA, rkn2@ princeton.edu, \\ imorris@princeton.edu \\ d Carleton Immersive Media Studio (CIMS), 1125 Colonel by drive, Ottawa, On, K1S 5B6 Canada, Mario.santana@ carleton.ca \\ e Nepal Engineering College \\ ${ }^{\mathrm{f}}$ Bhaktapur Municipality \\ g UNESCO Kathmandu Office \\ ${ }^{\mathrm{h}}$ Khwopa Engineering College \\ ${ }^{i}$ National Society of Earthquake Technology
}

\section{COMMISSION II}

KEYWORDS: IT Documentation, Risk Preparedness, Nepal, Built Heritage, Natural Hazards, Capacity-Building, Digital Workflows for Heritage Conservation, 3D Imaging, Georadar, Photogrammetry, Electronic Distance Measurements (EDM), Computer-Aided Drawing.

\begin{abstract}
:
On 25 April 2015, the Gorkha earthquake of magnitude 7.8, severely damaged the cultural heritage sites of Nepal. In particular, the seven monument zones of the Kathmandu Valley World Heritage Site suffered extensive damage. Out of 195 surveyed monuments, 38 have completely collapsed and 157 partially damaged (DoA, 2015). In particular, the world historic city of Bhaktapur was heavily affected by the earthquake. There is, in general, a lack of knowledge regarding the traditional construction technology used in many of the most important temple monuments in Bhaktapur. To address this limitation and to assist in reconstruction and rehabilitation of the area, this study documents the existing condition of different historic structures in the Kathmandu Valley. In particular, the Nyatapola Temple is studied in detail. To record and document the condition of this temple, a combination of laser scanning and terrestrial and aerial photogrammetry are used. By also including evaluation of the temple and its supporting plinth structure using non-destructive evaluation techniques like geo-radar and micro-tremor dynamic analysis, this study will form the basis of a structural analysis study to assess the anticipated future seismic performance of the Nyatapola Temple.
\end{abstract}

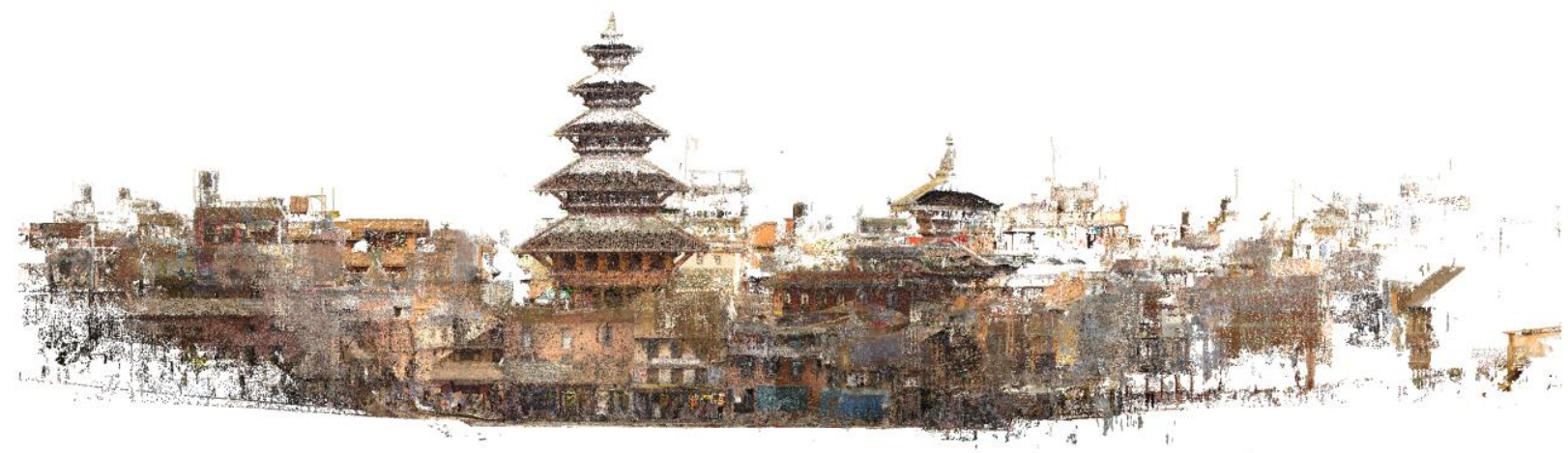

Figure 1. Taumadhi Square Point Cloud, Bhaktapur (Nepal)

* Corresponding author 


\section{INTRODUCTION}

\subsection{Scope and Objective of Research}

As a result of the Gorkha earthquake in Nepal on April 25, 2015, and the aftershock that followed on May 12, a large number of heritage structures in Nepal were destroyed or significantly damaged. In particular, the seven monument zones of the Kathmandu Valley World Heritage Site suffered extensive damage. Out of 195 surveyed monuments, 38 have completely collapsed and 157 were partially damaged (DoA, 2015). Bhaktapur, in particular, is a recognized UNESCO World Heritage Site (WHS) containing many structures of significant cultural and religious importance to the people of the Kathmandu Valley. Sustainable reconstruction and restoration of these heritage structures are critical to maintaining and restoring their outstanding value. To achieve this goal, it is important to work with local experts, engineers, and architects to understand the traditional construction technology and existing condition of these structures. This study includes the recording and documentation of representative buildings in the historic city of Bhaktapur, non-destructive investigation of the structures for construction information in preparation for later seismic structural analysis, and local capacity building.

The primary specific objectives of the study are to:

- Record information relevant to the structural performance of selected sites;

- Test performance of recording techniques to record Nepalese Heritage.

- Basic training to local Nepalese scholars and officers about the techniques used for data collection and processing;

\subsection{Part A: Recording and Documentation}

Managing the information of cultural heritage places should be an integral part of every heritage conservation project, but should also be an activity that continues long after the intervention is completed. This information is gathered through processes of documenting and recording site data through both traditional and advanced technologies. This information provides the basis for monitoring, management and routine maintenance of a historic site and facilitates the transmission of knowledge about the heritage places to future generations.

In 1996, the International Council on Monuments and Sites (ICOMOS) published principles for the "Recording of Monuments, Groups of Buildings and Sites" (ICOMOS 1996). Additionally, the International Charter for the Conservation and Restoration of Monuments and Sites (The Venice Charter, 1964) in Article 16 states "In all works of preservation, restoration or excavation, there should always be precise documentation in the form of analytical and critical reports, illustrated with drawings and photographs. Every stage of the work of clearing, consolidation, rearrangement, and integration, as well as technical and formal features identified during the course of the work, should be included. This record should be placed in archives of a public institution and made available to research workers."
In the case of the Kathmandu Valley, recording and documentation of the cultural heritage are as important as any other phase of conservation, from the repair, to alteration, to intervention work. Without documentation, important existing character-defining elements of the structures, in both a visual and structural sense, may be lost during restoration. It is particularly important to document these buildings to both record them in the case of future disasters and also to be able to evaluate their performance in the previous earthquake and the likely performance in the future.

\subsection{Part B: Structural Investigation}

Historic building investigation is needed for acquisition of data related to material properties, construction techniques, hidden voids, inclusions, masonry and timber decay, structural damages etc. (Binda, L. 2004). This information is used for structural analysis and for the choice of appropriate materials and techniques for localized or general repairs. Uncertainty in the mechanical properties of structural elements and the degree of degradation of those structural elements will significantly affect the results of any analysis. Recent advances in non-destructive techniques (NDT) have provided new tools to assess and evaluate existing historical masonry construction (Schuller, 2003). Due to the critical heritage value of the temple, destructive evaluation of the structure to determine material properties was not possible. Therefore, any analysis must rely on qualitative observation of material condition and damage and literature on the strength and material properties from similar structures. A bounded analysis will provide a range of structural behaviour based on a likely range of material properties.

To assess future performance, a seismic structural investigation of the tallest temple in Nepal, the Nyatapola temple in Bhaktapur, will be conducted. This temple survived the earthquake well with some minor damage to the upper tiers of the temple; however, it is not clear what the exact extent of the existing damage is, why this temple was resistant to collapse, or how the temple will perform in a potential future earthquake. One primary goal of this investigation is to determine what aspects of the traditional construction technology are present and had a positive influence on the seismic resistance of the temple.

This structural investigation portion of this study will address the following knowledge gaps for the Nyatapola temple, which will also have a consequence for other similar structures in the Kathmandu Valley:

- Traditional building construction technology

- Existing structural element condition (degradation of masonry unit, mortar, timber etc.)

- Identification of structurally vulnerable areas

- Structure of the plinth foundation

\subsection{Part C: Workshops on Documentation Training}

During the course of the field work, local Nepalese scholars and officers were encouraged to participate in the data collection and the processing. In particular, architects and engineers from the Department of Archaeology, Bhaktapur Municipality, Khwopa Engineering College and Khwopa College of Engineering directly worked on the project. The local scholars and officers were taught how to take images for photogrammetry, select locations for laser scanning, implement the georadar, take spherical panoramas, and process images for photogrammetry. A goal of this project was to ensure that local scholars and officials 
would be able to implement this methodology on other cultural heritage sites in need of documentation and analysis in the area.

\section{CASE STUDY}

\subsection{Field Work}

In this study, the authors collaborated with local institutions and professionals to conduct field work and build local capacity to do similar work in future. The focused project location for this study is Taumadhi Square in the Bhaktapur World Heritage Site (WHS). At the north end of the square is the five-tiered temple with a square footprint called the Nyatapola Temple. This temple is the tallest in Nepal and was constructed in 1701/1702 AD by King Bhupatindra Malla. Since its construction, this structure has resisted three major earthquakes (Mw 8.0 in 1833, Mw 8.4 in 1934, and Mw 7.8 in 2015) without major damage. It is clear that the study of this monument and its traditional construction technology has significant consequences for the seismic performance of other structures in the valley and equally important to digitally record structure before any other catastrophic disaster. The other major structure studied in Taumadhi Square is the Bhairavnath Temple on the eastern side, which is a three-tier temple with a rectangular footprint.

In addition to the Taumadhi Square, recording, documentation and non-destructive evaluation studies were conducted at historic sites throughout the Kathmandu Valley, including Bhaktapur Durbar Square (Vatsala Temple and Big Bell), Dattatreya Square (Pujari Math), and Kathmandu Durbar Square (Maju Dega Temple and Jaisi Dega Temple). During this fieldwork, the project team has worked closely with the Nepal Department of Archaeology, the UNESCO office in Kathmandu, the Bhaktapur Municipality, the Nepal National Society for Earthquake Technology (NSET) and with the local Khwopa Engineering College and Khwopa College of Engineering with the aim of building the capacity of national professionals working in the heritage sector and develop suitable methodologies for the onsite evaluation of the heritage structures in the Kathmandu Valley.

\subsection{Nyatapola (Five tier) Temple, Bhaktapur}

Nyatapola Temple is constructed on top of a $9 \mathrm{~m}$ tall high-rise plinth. The total height of the temple above ground level is approximately $33 \mathrm{~m}$. This is the only temple that is named after the dimension of architecture rather than from the name of the deity residing inside. According to the manuscript, that had records of daily work during the construction, it took nearly eighty-eight days to erect the structure since the laying of foundation stone (Shrestha, 2005, Vaidya, 2004). The design of the plinth is not well known and, because of the impressive size, is suspected to differ in construction technology from other temple plinths in the region. Because of this, the seismic influence of the plinth on the temple superstructure is not clear. Since there are many other monuments in the area that collapsed during the earthquake that also sits atop high-rise plinths, a better understanding of this particular plinth design and behaviour will contribute towards the conservation and restoration of those totally collapsed monuments.

In general, the workflow for carrying out this research project is divided into two parts as described previously: documentation and structural investigation. Many of these workflows were also applied to the evaluations of the other sites.

\section{METHODOLOGY}

\subsection{Part A: Recording and Documentation of Nyatapola Temple}

For recording and documentation of Nyatapola Temple, multiple digital tools were used. Recent developments in computer and information technologies have resulted in a wider range of options to document heritage structures with high precision.

The digital workflow used for field work was as follows:

- Establish a local coordinate system oriented to Azimuth using the Total Station, measuring control points (Targets)

- Using 3D Scanning and Photogrammetry to record the state of conservation of the outer surface of the sites

- Panoramic Photography for referential purposes

- Incorporation of subsurface documentation from georadar survey into digital models

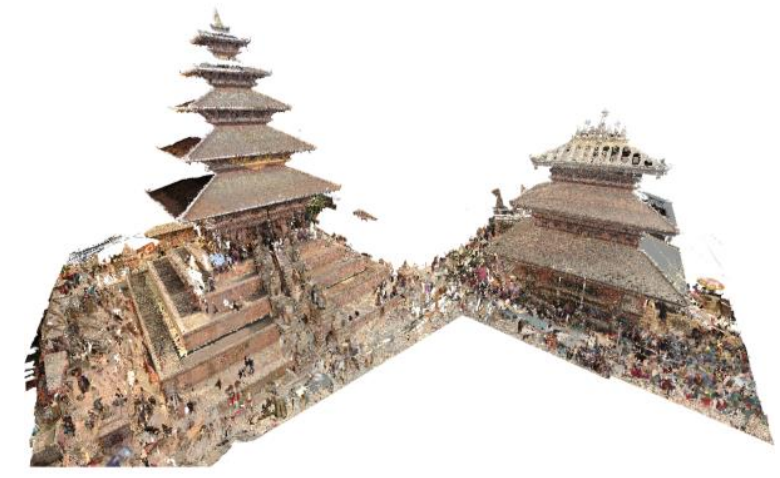

Figure 2. Nyatapola and Bhairavnath temples scan Point Cloud.

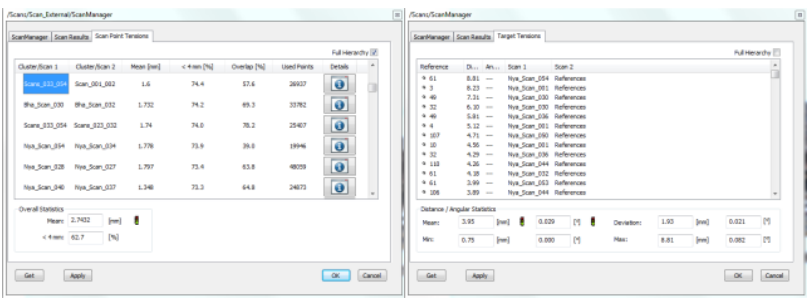

Figure 3. Accuracy of the point cloud registration

The present work utilized Faro focus ${ }^{3 \mathrm{D}}$ X330 for scanning and digital recording. Altogether, 49 scans were used from close range and long range to obtain the $3 \mathrm{D}$ point cloud of the standing structure. Cloud registration of these scans was performed and accuracy for was found to be within 3mm. (Figure 3-left)

A Leica total station was used to geo-reference the point cloud and provide additional survey controls. Surveyed control points within a shared local coordinate system were used to orient the models and combine data from laser scanning and photogrammetry. Error in the registration of all scans results for the Nyatapola with reference target is obtained to be $3.95 \mathrm{~mm}$ in average. (Figure 3-right)

As Nyatapola is the tallest temple in the surrounding region, it was not possible to obtain all details from the scanner alone. Hence additional aerial photogrammetry captured with a DJI Phantom4 drone was used with the same geo reference system. Common referencing provides an easy workflow to combine the laser scan point cloud with point cloud obtained from the UAV photogrammetry in Autodesk Recap. One of the major 
difficulties was capturing the images of the structure under the roof. Due to very dense urban houses near to structure it was not possible to obtain close range aerial photographs and also the light conditions were poor due to shadow. The challenges made it difficult to capture many of the details under the eaves of the roofs, especially wooden artefacts. Agisoft Photoscan was used to generate the point cloud from $5582 \mathrm{D}$ photos. Agisoft Photoscan is an advanced image based 3D modelling software for creating professional quality $3 \mathrm{D}$ content from still images. The generated point cloud had an average error of $2.85 \mathrm{~mm}$ in the registration with reference targets. (Figure 4).

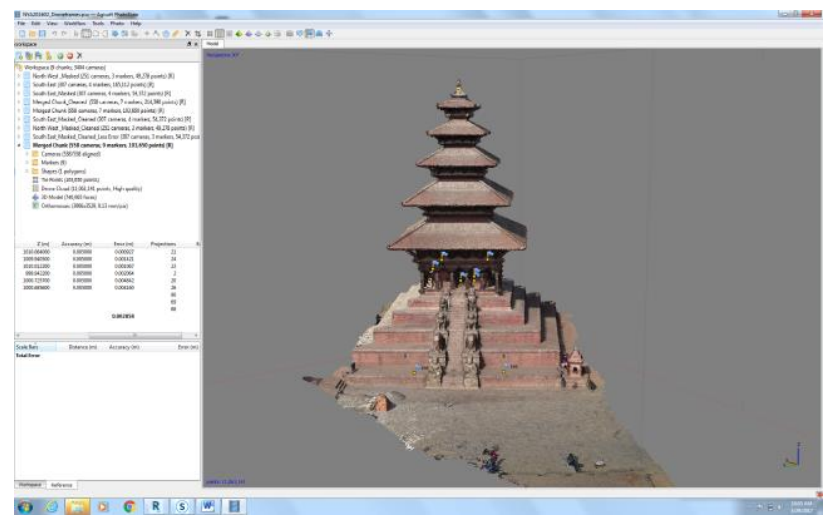

Figure 4. Aerial photogrammetry model using UAV

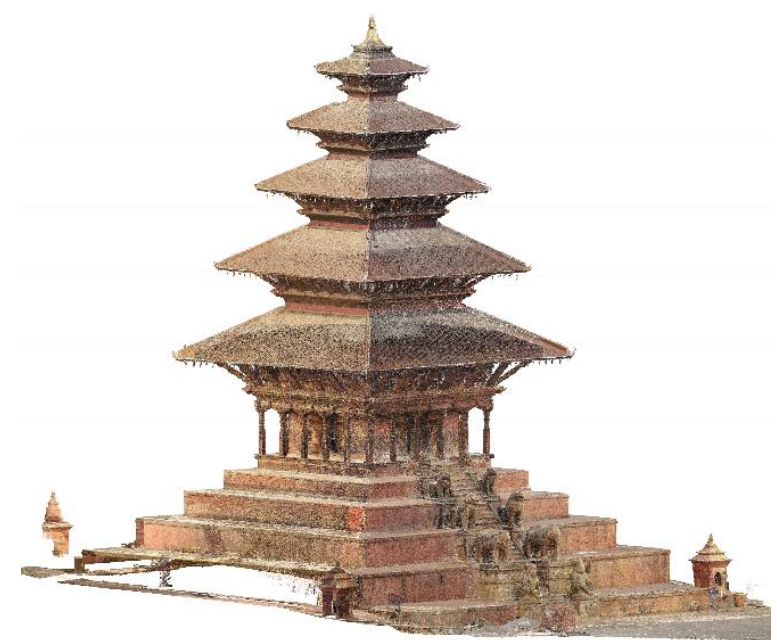

Figure 5. Combined 3D point cloud from laser scanner and aerial photogrammetry

Both point cloud from the laser scanner and the photogrammetric model were then registered together in Autodesk Recap to generate a complete model. The point cloud obtained from combine photogrammetry and laser scanning are used to develop high fidelity 3D models and orthographic images. (Figure 5)

In addition to laser scanning and aerial photogrammetry, close range terrestrial photogrammetry was also used for recording accessible areas of the Nyatapola Temple. Close range 2D photographs were taken using Nikon D800 DSLR Camera and were processed using Agisoft Photoscan software to generate the point cloud. This method is economic, easily learned, and easily accessible for any professionals in comparison to the laser scanner. Especially in the context of developing countries like Nepal, cost, availability of the equipment, and technical knowledge plays an important role in decision making.
A quick comparison was made for a segment of the structure. An open source software, Cloud Compare, was used to compare the point cloud obtained from the laser scanning and photogrammetric model of the northern façade of the ground floor (Figure 6). In total, 19 close range photos were used to generate a photogrammetric model. Finally, laser scanning cloud point data obtained from five close range scan position was coregistered with the close range photogrammetric cloud point data.

This comparison showed that there is a good correlation between the point cloud obtained from photogrammetric models with respect to laser scanning point cloud. More than $70 \%$ of point cloud distances between two models are within the range of $3 \mathrm{~mm}$. It is also found that more dispersion is occurred for the point cloud where the finely carved wooden artefacts were present, like Torana just above the door (Figure 7, 8). Therefore, photogrammetric models are an accurate and accessible method whose only major drawback in this application is regenerating very detailed $3 \mathrm{D}$ point cloud for carved wooden features.
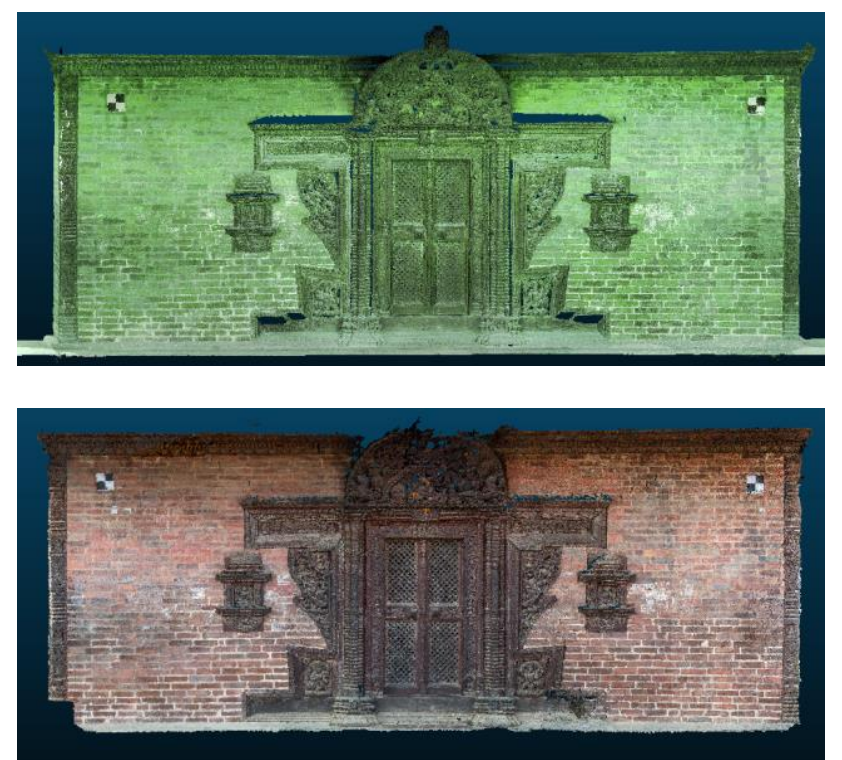

Figure 6. Laser scanning point cloud (up) and photogrammetric (bottom) point cloud

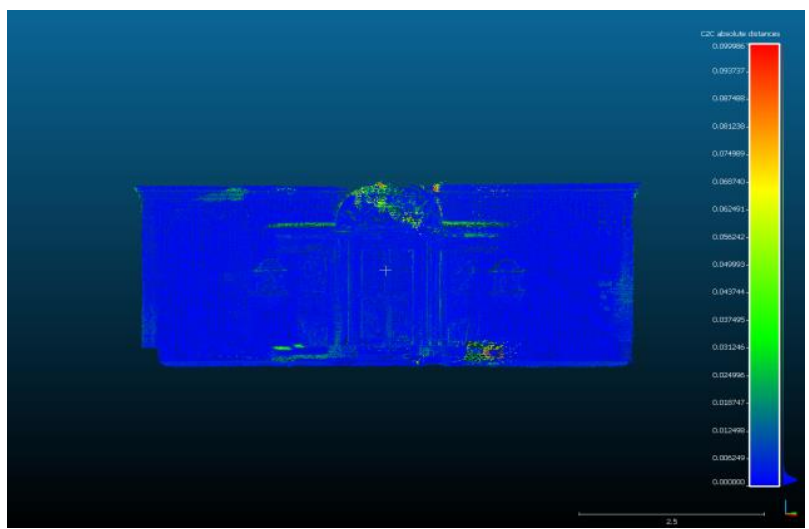

Figure 7. Dispersion results in photogrammetric point cloud compared to laser scanning point cloud 


\subsection{Part B: Structural Investigation}

\subsubsection{Construction Technology of Nyatapola Temple}

The temple is constructed in traditional Newari tier temple architecture during early $18^{\text {th }}$ Century by King Bhupatindra Malla. Traditional construction materials like burnt brick, mud mortar, stone, clay tile, metal (copper and brass) and timber were used for the construction. Five different types of timbers, which are Chap (Michelia Champaca), Sal (Sorea robusta), Salla (Pinus roxburghii), Deodar (Cendrus deodara) and Gobresalla (Pinus roxbughii) were used in the construction (Vaidya, 2004). Two major features of this remarkable construction are the use of a higher plinth and no internal floors above the first-floor level forming open well type structure (Figure 9, 10).

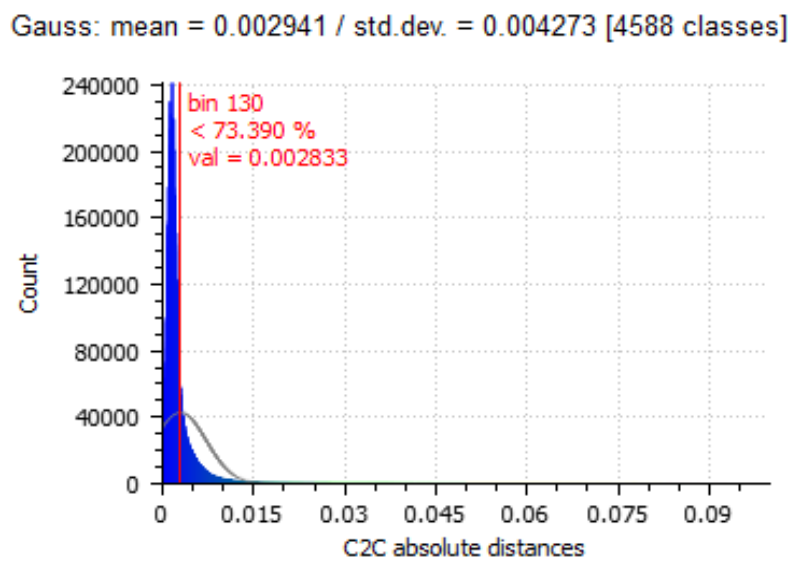

Figure 8. Gauss Distribution for cloud to cloud absolute distances

The five levels of plinth come to a full height of approximately $9 \mathrm{~m}$. The construction of high-rise plinth temples in Kathmandu Valley started in the early $16^{\text {th }}$ century with the construction of Taleju Temple (1564 AD) in Kathmandu Durbar Square, which is the first-tier temple having more than two tiers (Wisner, 1978). Construction of high rise plinths may have a direct relation to the height of the structure that is going to be constructed. Primary examples of this relationship are Maju Dega and Jaisi Dega, each constructed with three-tiered high-rise plinths. The only exception to this trend is Kumbhewor in Patan, which has five tiered construction without a high rise plinth.

The ground floor plan is symmetrical with a perimeter wall of approximately $1.45 \mathrm{~m}$ thick and colonnade area. The main wall is constructed with brickwork and mud mortar, with a door on each side. The colonnade roof is supported by six wooden timber post on each side. Timber posts in the colonnade are braced with horizontal beams in the base level and floor level. There is a stone block below each column post. The timber floor of the colonnade is elevated above a void to encourage evaporation and prevent the wood from decay and damp. (Figure 9, 10)

The main walls extend up to the second floor; in the first floor there exists another external wall just above the column post of collonade. After the first floor, the interior of the temple is open (there are no floors), hence it is difficult to reach the upper levels of the structure and they were not directly scanned. (Figure 9,10) The walls are connected to timber beams at different levels by wooden nails. As the temple superstructure extends upward, the plan area is gradually reduced. This is accomplished by constructing the walls of each level on an axis which is offset inwards from the level below, i.e., the outer edge of the upper wall is aligned roughly with the center of the wall below. The walls of each level were constructed just above timber beams.

\subsubsection{Recording of existing damage condition}

Major damage is concentrated in upper tier of structure and wall was found to be partially collapsed. The upper tier was recorded to be collapsed in previous $1934 \mathrm{AD}$ earthquake as well and which is reconstructed later on. A major renovation was done during 1996 AD by Bhaktapur Municipality in which majorly roof was repaired wooden post in the upper tier was replaced after founding it was decayed (Figure 11) (Bhaktapur, 1998). This also suggests that there may be the presence of the timber element inside walls in below level as well.
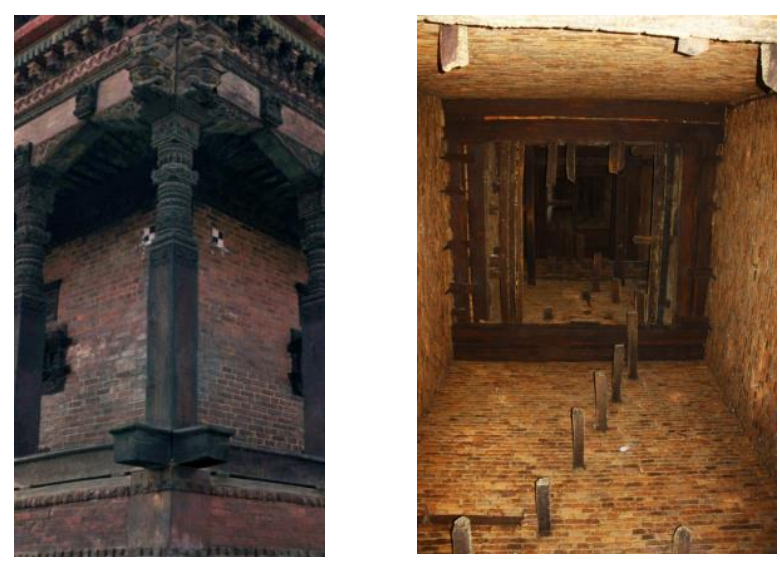

Figure 9. Detail of Column post (left) and ceiling view of inside from first-floor level (right)
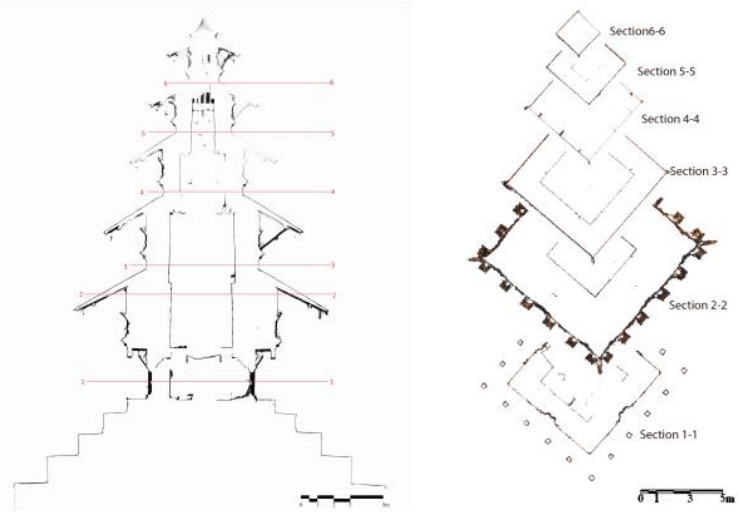

Figure 10. Schematic representation E-W section of Nyatapola temple and the floor plans generated from the point cloud
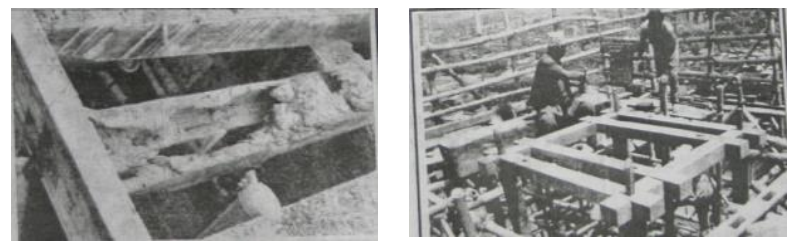

Figure 11. Replacement of decayed timber during 1996 AD restoration work 
Existing damage in the structure is digitally recorded using the photogrammetry and laser scanning data. Partially collapsed top wall was found to be torsionally distorted by approximately $3.557^{\circ}$ clockwise in respect to the base of the superstructure. However, several shear cracks developed in the doorway on all four-side wall also identified. High-quality orthophotos are generated from the close-range laser scanning and photogrammetric models. These orthophotos were used for mapping existing cracks in the wall (figure 12). Mapping of these cracks will then be introduced in the finite element modeling for assessing the existing performance of structure in future.

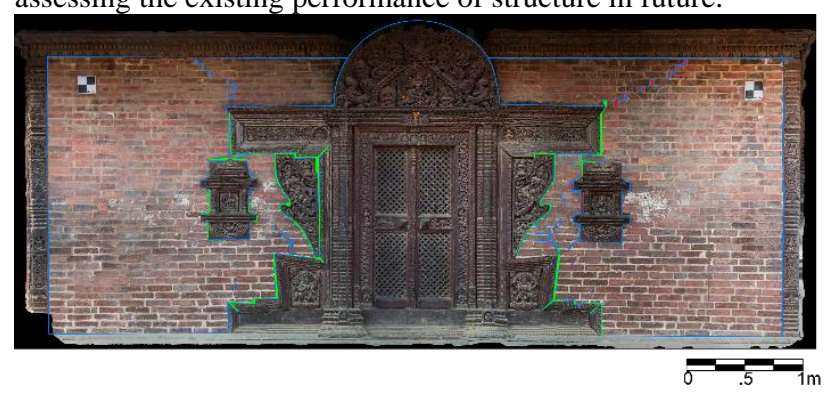

Figure 12. Mapping of existing cracks in structural wall

\subsubsection{Geo- Radar Investigation}

In addition to the surface documentation using laser scanning and photogrammetry, non-destructive techniques were used to investigate the inner composition of structural elements. For this purpose, geo-radar survey was conducted on the masonry walls (with a $900 \mathrm{MHz}$ antenna) and plinth (with a $270 \mathrm{MHz}$ antenna) of the Nyatapola temple. Georadar is a travel time tomography method that works by recording electromagnetic waves which are reflected at dielectric interfaces (different materials). Georadar allows the identification of morphology, voids, discontinuities, and damage in masonry walls. (Binda, 1994, Binda, 1997, Binda, 1998, Colla, 1997)

The first major area of georadar (or GPR) investigation was the construction of the plinth. At Jaisi Dega, previous excavations of the plinth were carried out by the Department of Archaeology. These excavations provide information about the thickness of different layers that enable estimates of the velocity and dielectric constant for the areas with a brick in mud mortar. With this information, the radargrams collected with the $270 \mathrm{MHz}$ antenna on the plinth at Nyatapola can be interpreted by comparison to the radargrams collected in the same manner at Jaisi Dega. (Figure 13,14) Scans collected on the vertical faces of each plinth level indicate that, for both structures, the plinth is constructed of brick masonry with mud mortar as deeply as the georadar can penetrate (about 1.5m). (Figure 14) Additionally, the comparison with Jaisi Dega indicates that the outer surface of each plinth level is constructed with mud mortar as a regular brick masonry wall which extends down through the plinth to the lowest foundation level. In between these walls, the construction is dry stacked bricks, with less regular courses and no mud mortar. (Figure 14)
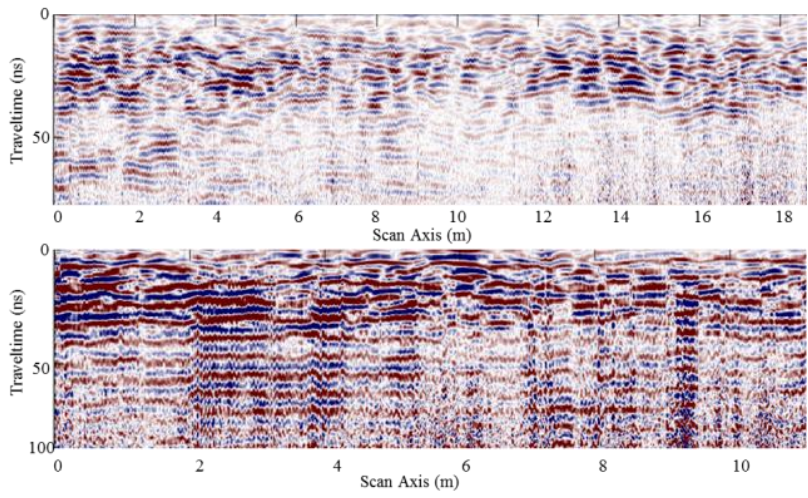

Figure 13. $270 \mathrm{MHz}$ scans of vertical surfaces of the brick plinth of Nyatapola. Note the different display contrasts and horizontal axes.

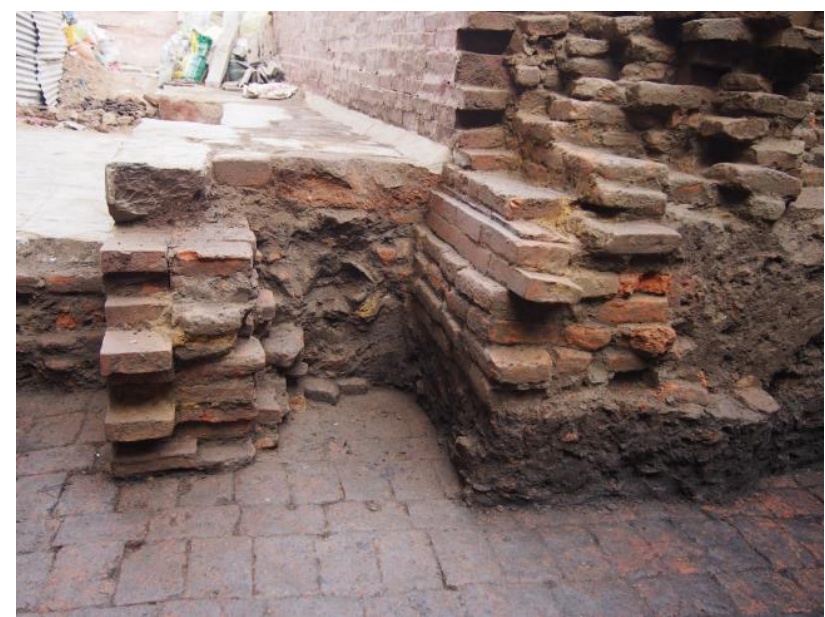

Figure 14. Excavated section at Jaisi Dega showing stacked bricks in the upper right with mud mortared bricks on the vertical faces of the plinth.

The second major area of investigation was the construction of the walls, specifically investigating whether there are internal timber elements or other methods of ensuring vertical continuity between each level with offset walls. Much traditional construction from this period contains internal timber elements (Bernier, 1979), but it was unknown if Nyatapola Temple followed in the same tradition. This investigation was carried out with the $900 \mathrm{MHz}$ antenna on the exterior of the lowest set of perimeter walls and interior of the ground and first floor of the temple. The ground level scans (at the top of the plinth) did not provide conclusive evidence about the nature of probable timber elements in the walls, but there is an obvious internal discontinuity. (Figure 15) This interface occurs directly under the outer edge of the second-floor wall, underneath its corner. This interface does not indicate a single vertical piece of timber but may indicate a more extensive internal framing system that supports the superstructure. In scans of the first floor, there is a vertically continuous internal element that is likely timber. (Figure 15) Because higher levels were inaccessible for scanning, the vertical continuation of timber elements cannot be confirmed in scans. However, because traditional construction practices are followed in the first two levels of the superstructure, it is likely that they are also followed in the upper levels and the timber continues vertically. Scans of the inner sanctum at Nyatapola did not provide enough information to compare to scans of the inner sanctum at Jaisi Dega. 

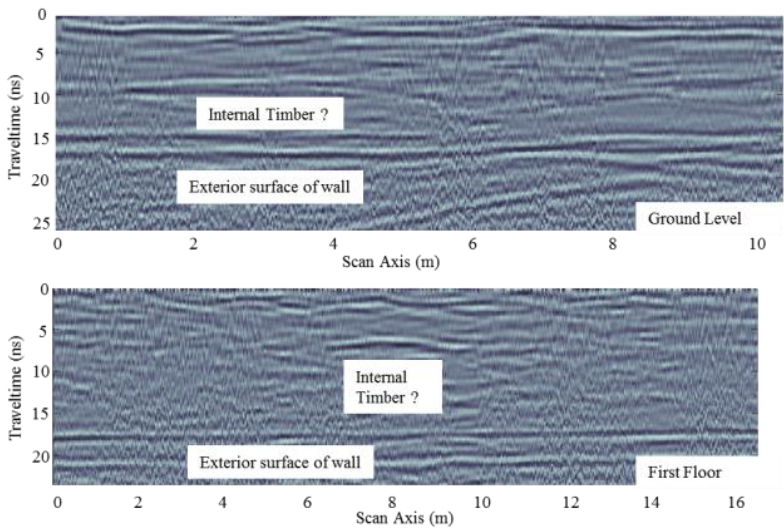

Figure15. Internal elements with vertical continuity in each level in the ground floor (top) and first floor (bottom) walls.

\subsection{Other non-destructive investigations}

In addition, micro-tremor testing will be conducted on the plinth to determine its dynamic properties by measuring the dynamic response to a very small excitation. Ambient vibration will also be used to determine the dynamic response. The dynamic response will be used for further structural investigation of the seismic response of the temple.

Following the collection of geometric, morphological, damage, and other information on structural elements, a finite element analysis or combined discrete element analysis will be conducted to evaluate the seismic behaviour of the Nyatapola Temple in a separate study.

\section{SCOPE OF ADDITIONAL WORK}

In addition to the documentation and evaluation of Nyatapola Temple, the Carleton University - Princeton University team worked in collaboration with local Nepali colleagues to perform the following additional documentation and analysis work:

\section{At Bhaktapur Durbar Square:}

- Vatsala Temple - Georadar evaluation of the plinth structure to confirm excavation results, determine inner sanctum construction, and use this information to validate survey parameters (velocity and dielectric constant) and construction material reflections.

- Big Bell - Georadar evaluation of the supporting structure and photogrammetry.

At Dattatreya Square:

- Pujari Math - Laser Scanning of the interior and exterior, georadar evaluation of the interior wall, and exterior photogrammetry.

At Taumadhi Square:

- $\quad$ Bhairavnath Temple - Complete georadar evaluation of the walls, laser scanning of the interior and exterior, terrestrial and aerial photogrammetry, ambient vibration dynamic analysis.
At Kathmandu Durbar Square:

- $\quad$ Maju Dega Temple - Georadar evaluation of the plinth and inner sanctum.

- Jaisi Dega Temple - Georadar evaluation of the plinth and inner sanctum to confirm excavation predictions and compare to Nyatapola.

The next steps of this study are:

- 3D Modelling of the selected sites using CAD, Revit, and Rhino

- Develop a framework for the Finite Element Modelling of the structure

- Prepare a report describing the workflows developed and results of the modeling

- Draft recommendation for further analysis of historic structures

\section{CONCLUSION}

The research aims to contribute to the conservation process for the historic buildings in Bhaktapur, Nepal which suffered damage in the 2015 earthquake. The outcome of research addresses the important difficulties related to the preparation of existing condition drawings, acquisition of data on material properties, internal morphology and damage, and determination of structural load paths.

In this study, an existing methodology for digital recording is implemented for recording heritage structure of Kathmandu Valley and comparative studies were made. This will contribute towards adaptation of the sustainable recording methodology suitable for the Kathmandu Valley Heritage.

Furthermore, uncertainty related with timber structure inside wall and construction typology of high rise plinth is also studied using georadar, a non-destructive technique. This will provide a base for understanding the internal morphology of masonry wall and study a relationship between the superstructure and plinth and its effect in the performance of superstructure during a seismic event.

This can be a basis for further structural analysis providing information about the traditional construction technology in the region and insights into the seismic resilience of the Nyatapola temple. This will help the local government plan and prepare restoration documents of totally collapsed monuments for which information about construction technology does not exist.

\section{ACKNOWLEDGEMENTS}

The authors would like to extend gracious thanks to the people of Nepal through their national and local government agencies including the Department of Archaeology and the Municipality of Bhaktapur. This work could not have been conducted without the collaboration of the Khwopa Engineering College and Khwopa College of Engineering, the UNESCO office in Kathmandu, the Nepal National Society for Earthquake Technology (NSET).

This work was supported financially by National Science and Engineering Research Council (NSERC) through its CREATE and Discovery Grant programs. 


\section{REFERENCES}

Bernier, R.M., 1979. The Nepalese Pagoda Origins and Style

Bhaktapur., 1998. Nyatapola Jirnodwar ko Bibaran, Bhaktapur Monthly Magazine Vol. 150, pp. 18-26

Binda, L., Colla, C. \& Forde, M.C.,1994. Identification of moisture capillarity in masonry using digital impulse radar, $J$. Construction \& Building Materials, Vol. 8, No. 2, pp. 101-107.

Binda, L., Saisi, A., Tirabosehi, C., 2001. Application of Sonic Tests to the Diagnosis of Damage and Repaired Structures, Non Destructive Testing and Evaluation Int ., 34(2), 123- 138.

Binda, L, Saisi, A., Gerosa, L. \& Lenzi, G., 1997. GPR application to multiple leaf stone masonries, Proc. of the International Colloquium "Inspection and Monitoring of the Architectural Heritage", IABSE-ISMES, pp. 215-222.

Binda, L., Lenzi, G. \& Saisi, A., 1998. NDE of masonry structures: use of radar test for the characterisation of stone masonries, J. Non Destructive Testing and Evaluation International ed. Elsevier Science Ltd., Vol. 31, N.6, pp. 411419.

Binda, L., 2004. The importance of investigation for the diagnosis of historic buildings: application at different scales (centres and single buildings). Proc of 4th international seminar on structural analysis of historical constructions, Padova, Italy. Vol. 1. 2004.

Colla, C., Das, P.C., McCann, D. \& Ford, M.C., Sonic, electromagnetic \& impulse radar investigation of stone masonry bridges, J. Non Destructive Testing and Evaluation International, Vol. 30, No. 4, pp. 249-254, 1997.

DOA 2015, Preliminary list of affected monuments by the Earthquake on 25 April 2015, Department of Archaeology, Nepal.

ICOMOS, 1965. International charter for the conservation and restoration of monuments and sites (The Venice charter 1964). International Council on Monuments and Sites.

ICOMOS, 1996. Principles for the Recording of Monuments, Groups of Buildings and Sites (1996). , (October).

Shrestha, Sukra S., 2005. Research Note Work Index of Nytapola Temple. Contribution to Nepalese study. Vol 32. No. 2. 267-275

Schuller, Michael P., 2003. Nondestructive testing and damage assessment of masonry structures. Progress in Structural Engineering and Materials 5.4: 239-251.

Vaidya. Janak. L. 2004. Siddhagni Kotyahuti Devala Pratistha

Wiesner. U., 1978, Nepalese Temple Architecture: Its characteristics and its relations to Indian Development 